The final, definitive version of this paper has been published in Childhood - A Global Journal of Child Research, Vol. 20(1), February 1, 2013, pp.98-114, by SAGE Publications Ltd, available at http://online.sagepub.com . All rights reserved. CMaria João Leote de Carvalho (CESNOVA - FCSHUniversidade Nova de Lisboa, Portugal)

\title{
Children's perspectives on disorder and violence in urban neighbourhoods
}

\section{Abstract}

Based on the analysis of 312 children's neighbourhood drawings and narratives, in this article we discuss children's socialization in six public housing neighbourhoods in Portugal, through children's personal accounts of their lives. We then examine their perspectives on disorder and violence. Most complained about living there, referencing how social and spatial segregation, associated to high exposure to violence, affect them. There is a 'normalization' of disorder and violence, due to its intense frequency, mainly in public spaces, which has an effect on children's socialization, especially those to whom street is 'the' central place in daily life.

Keywords: children, urban violence, public housing neighbourhoods, socialization, drawings

The discussion on violence repeatedly focuses on its expression in urban spaces, associated with urbanization processes, which has effects that are intensely felt on populations, most notably in children's socialization (Sampson and Laub, 1994; Popkin et al., 2000). New directions for the study of urban violence have become more visible as several authors emphasize how the social organization of a given 
The final, definitive version of this paper has been published in Childhood - A Global Journal of Child Research, Vol. 20(1), February 1, 2013, pp.98-114, by SAGE Publications Ltd, available at http://online.sagepub.com . All rights reserved. CMaria João Leote de Carvalho (CESNOVA - FCSHUniversidade Nova de Lisboa, Portugal)

residential area is a key factor to prevent physical and social disorders, ${ }^{1}$ violence and crime (Morenoff et al., 2001). Currently, the perception of living in risk societies is strongly diffused and the fear of violence affects our daily lives (Beck, 1992; Lee, 2001; Gill, 2007). However, children's perspectives on these issues are rarely discussed.

The complexity of children's lives in contemporary urban settings is expressed in the coexistence of multiple ways of life and experiences of violence that are generally associated with different social status corresponding to different contexts. Everyday life occurs in a specific place, a specific social space, which children interpret, use, appropriate, (re)construct and (re)present in a different way from adults (Corsaro, 1997). Living in an urban area is as much as negotiating relationships with others as well as experiencing material places and spaces (Christensen and O'Brien, 2003), and the neighbourhood where children live clearly influences the choices and opportunities they have at their disposal, and how they stand towards disorder and violence (Kingston et al., 2009).

Children do not merely internalize the external adult culture. Rather, they become a part of adult culture, therefore contributing to its (re)production through their negotiations with adults and their peers' cultures, in a fragmented puzzle of social and educational references (Corsaro, 1997). Children contribute to their socialization and, in consequence, to the edification of society (James and Prout, 1990; Mayall, 
The final, definitive version of this paper has been published in Childhood - A Global Journal of Child Research, Vol. 20(1), February 1, 2013, pp.98-114, by SAGE Publications Ltd, available at http://online.sagepub.com . All rights reserved. CMaria João Leote de Carvalho (CESNOVA - FCSHUniversidade Nova de Lisboa, Portugal)

2002; Wyness, 2006). They must be viewed as an active part in building society, through participation in time and space in which they increasingly find themselves away from the close supervision of the family (Almeida, 2009). Thus, considering children's insights about disorder and violence in urban neighbourhoods is essential to empower children's participation in city life, especially in urban planning processes.

\section{Children's place(s) in cities}

In this era of globalization in which the stratification of resources in space remains at the core of society's organization, paradoxically, despite all the progress and development, social inequalities have grown, perhaps even in an exacerbated mode (Sassen, 2001, cit. in Sampson, 2002). On one hand, globalization has enhanced a sense of dispossession of the city, by the diffusion of lifestyles which are not limited to the city's territorial limits; on the other, urban space social division has led to segregation, resulting in unequal opportunities in the access to material and symbolic resources, which affect different social groups.

Whilst major changes in territory management have occurred, children's lifestyles in modern cities have undergone great changes as well (Ennew, 1994; Holloway and Valentine, 2000b; Christensen and O'Brien, 2003). Complex images and representations of social risk and childhood emerge associated to multiple reflections 
The final, definitive version of this paper has been published in Childhood - A Global Journal of Child Research, Vol. 20(1), February 1, 2013, pp.98-114, by SAGE Publications Ltd, available at http://online.sagepub.com . All rights reserved. CMaria João Leote de Carvalho (CESNOVA - FCSHUniversidade Nova de Lisboa, Portugal)

that position children as objects in a variety of situations (parental love, education, and others) (Lee, 2001).

Consideration of children's places in cities is inseparable from understanding the importance attributable to time in children's lives. In recent years, deep changes have been observed in the ways children organize their time and daily lives. The decrease of free time to use in a spontaneous way, in association with the increased participation in organized activities based on planned time, marks many children's lives worldwide. The significant institutionalization of children's routines and practices highlights the parental and organizational restrictions imposed on children, which is reflected in their development. As Neto (2005: 24) suggests 'today, life in the city is desperately rational and adult, which definitely constitutes a symbolic violence that marks the construction of childhood and limits children's imaginary, fantasy and social learning. ${ }^{2}$

Subjectivity established by adults through various ways of looking at the city determines the conditions of children's lives (Ennew, 1994). The population increases, traffic density and fear of crime are some of the factors that support parental anxiety about their own safety and that of their children. Almost everything related to the street and other public spaces raise public suspicion and fear (Ennew, 1994). The more adults emphasize security issues in public spaces, the more cities become less child friendly, decreasing the possibility of children accessing different 
The final, definitive version of this paper has been published in Childhood - A Global Journal of Child Research, Vol. 20(1), February 1, 2013, pp.98-114, by SAGE Publications Ltd, available at http://online.sagepub.com . All rights reserved. CMaria João Leote de Carvalho (CESNOVA - FCSHUniversidade Nova de Lisboa, Portugal)

types of experiences. Children's play in streets is seldom seen freely in urban contexts since there is now equipment specially designed for this purpose, such as playgrounds, one of the hallmarks of present-day childhood (Karsten, 2003; Neto, 2005). Parental perceptions of risk and (in)security tend to result in the child's confinement to enclosed spaces, specialized 'islands', mainly in the family, school or leisure places, being registered a loss of freedom to use public spaces (Holloway and Valentine, 2000a; Christensen and O'Brien, 2003).

Based on the fear of seeing a child at risk, 'hyper vigilance' has become one of the images of contemporary societies, expressed in an increasing privatization of space, equipment and activities for childhood (Katz, 2005). Ignoring that is not possible to protect a child from all social dangers (Ennew, 1994), parental anxiety tends to be exacerbated and translated into a polymorph of actions and systems, such as nannycams or mobile phone with GPS (Katz, 2005). Children's activities are becoming increasingly formal in which the main effect is the scarcity or even absence of truly free time and the possibility to spontaneously explore streets, public spaces and natural environments. Urban life expresses the use of space in specialized forms, and often, home, school, play or work places are in multiple settings, which highlight the growing use of cars and other forms of transportation.

However, this is not a linear process and does not affect all children in the same way (Christensen and O'Brien, 2003). It results in marked differences in access to 
The final, definitive version of this paper has been published in Childhood - A Global Journal of Child Research, Vol. 20(1), February 1, 2013, pp.98-114, by SAGE Publications Ltd, available at http://online.sagepub.com . All rights reserved. CMaria João Leote de Carvalho (CESNOVA - FCSHUniversidade Nova de Lisboa, Portugal)

resources according to social origin and the nature of the areas where children are located or live (Almeida, 2009). (In)Security sharpens the gap between people's different positions in the social structure (Katz, 2005), and one of the most important urban developments in western societies is related to the profound changes in children's mobility and autonomy in cities. Several studies show that the use of public space by socially disadvantaged children tends to be done more without parental supervision, with a level of greater mobility and autonomy, than among those who belong to middle and upper social classes and who are more likely to participate in organized and formal activities (Valentine, 2004). This might expose the first ones to higher levels of violence and disorders (Sampson and Laub, 1994), which confirms that poorer children are likely to be more affected by social risks in using public spaces than children of different social status (Christensen and O'Brien (2003).

More than ever today children's rights were at the core of social policies, however, it is in cities that inequalities and paradoxes of its implementation will be felt most. Social fragmentation and social division of space, so characteristic of urban life, reinforce the notion of existing 'geographies of insecurity and fear' (Body-Gendrot, 2001) and adults' attitudes towards children tend to ignore children's feelings about these issues. Childhood is thus crossed by several phenomena at the same time, and in some cases "children are becoming "empowered", while in others they are 
The final, definitive version of this paper has been published in Childhood - A Global Journal of Child Research, Vol. 20(1), February 1, 2013, pp.98-114, by SAGE Publications Ltd, available at http://online.sagepub.com . All rights reserved. CMaria João Leote de Carvalho (CESNOVA - FCSHUniversidade Nova de Lisboa, Portugal)

becoming more institutionalized and subject to adult control' (Madge, 2006: 10). The inconsistencies in the enforcement of children's participation in social life accentuate their vulnerability in two ways. On one hand, they are overrepresented in poverty and social exclusion indicators and as victims of violence, particularly in urban areas. On the other hand, they are invisible and lack power at social and political decision centres (Almeida, 2009).

\section{Methodology}

The current investigation is part of a larger study, a $\mathrm{PhD}$ research project in sociology concerning childhood, violence and delinquency in Portugal (Carvalho, 2010). Aiming to achieve a better understanding of children's socialization processes considering multi-problematic spaces, mainly about their involvement in delinquency, between 2005 and 2009, a case study has been carried out on six public neighbourhoods, involving a combination of qualitative methodologies. This article presents the results obtained at the first stage of the research, taking as a starting point the purpose to discuss how children represent living in their neighbourhoods. Based on the analysis of children's neighbourhood drawings and narratives, the intention was to identify the main contours of children's socialization in the field, through their own accounts of their lives, and to examine their perspectives on disorder and violence. 
The final, definitive version of this paper has been published in Childhood - A Global Journal of Child Research, Vol. 20(1), February 1, 2013, pp.98-114, by SAGE Publications Ltd, available at http://online.sagepub.com . All rights reserved. CMaria João Leote de Carvalho (CESNOVA - FCSHUniversidade Nova de Lisboa, Portugal)

\section{Research context and participants}

Participants were 312 schoolchildren aged 6-13 $(M=8.38)$ attending two primary state schools $\left(1^{\text {st }-4^{\text {th }}}\right.$ grade), living in one of the selected six public housing neighbourhoods in Oeiras, a county in the Lisbon Metropolitan Area. Exactly half of the participants were girls (50.0 percent, $n=156)$ and the other half were boys. To assess age effects, the children were grouped according to age: 6 to 9 years old (75.0 percent, $n=236$ ), and 10 to 13 years-old (25.0 percent, $n=76$ ). Most were African origin from the former Portuguese colonies (62.8 percent, $n=196)$, mainly The Cape Verde Islands, 9.2 percent $(n=29)$ were Gypsies, and 28.0 percent $(n=87)$ were Caucasian. Nearly all were from lower SES households, with 86.7 percent $(n=271)$ getting financial support from social services at schools.

According to the Portuguese law, since the participants were under the age of 18 , the study had been previously explained not only to children, but also to their parents or legal guardians, who had to give permission. Letters of consent were sent to them in order to confirm their allowance to children's participation, and through informed consent children expressed their willingness to take part in the research.

The neighbourhoods covered in this study were chosen because they experience relatively high levels of social deprivation, violence and crime, although being located in one of the richest counties in the country, and the first one to have 
The final, definitive version of this paper has been published in Childhood - A Global Journal of Child Research, Vol. 20(1), February 1, 2013, pp.98-114, by SAGE Publications Ltd, available at http://online.sagepub.com . All rights reserved. CMaria João Leote de Carvalho (CESNOVA - FCSHUniversidade Nova de Lisboa, Portugal)

eradicated slums in 2003 , by promoting public housing policies, most notably since the 1980s.

One of the main features of these territories is that they are all close to each other instead of being near other kinds of residential areas. Five of them create a homogeneous continuum in this county territory, and the sixth is less than a half a mile away from the other five. When entering the field, we started to consider each neighbourhood, but soon the confrontation with the ethnographic notes and the official data collection forced us to go in a different direction. Although there are not two equal neighborhoods, many of their traces of characterization are common, highlighting the importance of considering the analysis of their interdependence and socio-spatial dynamics. It is a whole socially disadvantaged universe, with no significant socio demographic differences. Besides, since many families have relatives in these different neighbourhoods, and the services, schools and other facilities created to serve the communities are located in various areas, children and residents have high mobility. So, it was necessary to conceptualize each neighbourhood as a node of a wider network of spatial relations in the metropolis, which affects the children's socialization (Kingston et al., 2009).

For ethical reasons, in order to protect the participants and guarantee their privacy and anonymity, the neighbourhoods' real names have been replaced by others defined through colours: Yellow, Pink, Grey, Green, Blue and White. According to 
The final, definitive version of this paper has been published in Childhood - A Global Journal of Child Research, Vol. 20(1), February 1, 2013, pp.98-114, by SAGE Publications Ltd, available at http://online.sagepub.com . All rights reserved. CMaria João Leote de Carvalho (CESNOVA - FCSHUniversidade Nova de Lisboa, Portugal)

official council data, this research context included 1,700 homes, 5,000 residents (1,552 tenant families and 139 families who owned homes), of whom $33.2 \%$ were between 0 and 18 years-old.

\section{Procedures}

Data collection took place from 2006 to 2008. In small groups in their classrooms, children were asked by the author if they could do an individual drawing about their neighbourhood. We have been open-ended in our approach by not having one specific theme, allowing them to bring up whatever they wanted about this issue. Each child was given an A4 sheet of white paper: the area where the drawing should be executed had been bordered, and another space for its legend, for those who were already able to write. When they finished, there was an individual conversation with every single child, started with the author asking the child to describe and explain his/her drawing, in order to register his/her interpretation, which led to the identification of the content and meaning that each one gave to his/her own work. In this process emerged the need to follow children's ideas and thoughts. Without the observation of this principle the children's discussions with the author about the drawings would have been less productive. Depending on the nature and content of these situations, each discussion went in different directions and it is not possible to indicate an average time, given the diversity of cases. 
The final, definitive version of this paper has been published in Childhood - A Global Journal of Child Research, Vol. 20(1), February 1, 2013, pp.98-114, by SAGE Publications Ltd, available at http://online.sagepub.com . All rights reserved. CMaria João Leote de Carvalho (CESNOVA - FCSHUniversidade Nova de Lisboa, Portugal)

Three boys (one 8-year-old, and two 11-year-olds) refused to draw and left the paper sheet blank. When describing their decision-making process, they expressed feelings of devaluation regarding the context in which they lived: 'Drawing the neighbourhood?!... No, no, I don't like it!', 'There's nothing here that I do like, I do not like to live here!' and 'The neighbourhood... I don't do anything, I don't know anything!'

\section{Data Analysis}

Taking up the children's drawings as a methodological tool in sociological research, rather than limiting the analysis to the final product, which would lead to the adult's interpretation, it is essential to listen to what children have to say about it, and what reactions they have about the process. As a communicative action, drawings are much more than a mere attempt to represent the outside world, since by assigning particular meaning and content, children go beyond the practice of a visual realism (Gardner, 1990) and explore specific forms of social action that they decode before others, allowing to enter their social worlds and into their most significant relationships and forms of participation in social life (Anning and Ring, 2004; Kostenius, 2011).

Although they may draw on the basis of models they have access to, they never fail to represent what they want with a specific reason (Anning \& Ring, 2004). As a 
The final, definitive version of this paper has been published in Childhood - A Global Journal of Child Research, Vol. 20(1), February 1, 2013, pp.98-114, by SAGE Publications Ltd, available at http://online.sagepub.com . All rights reserved. CMaria João Leote de Carvalho (CESNOVA - FCSHUniversidade Nova de Lisboa, Portugal)

product of individual action in a given space and time, a drawing symbolically articulates the child's various living conditions. Thus, for its interpretation in a sociological perspective, it is necessary to take into account three guidelines: first, the drawing is an unique product, unique of a particular child; secondly, it is a social artefact, that allows one to unveil the rules and the values in children's life through access to various cultures of childhood; thirdly, it is a symbolic object giving expression to a specific generational group, childhood. Therefore, 'the drawing of a child is, after all, the drawing of a world" (Sarmento, 2007: 20). ${ }^{2}$

In order to analyse the drawings from as many different angles as possible (Kostenius, 2011), the data was firstly organized according to age groups, combining both drawings and narratives as a unit, and its analysis was based on a multiple step process conducted to explore differences and similarities in children's productions. All the material collected were subject to content analysis, where it was possible to cross the graphic representation (non verbal language) with the individual narratives (text) told by children. In each work, both form and content were considered, the themes and sub-themes were identified, and cross tabulations and chi-square analyses were performed to test age and gender differences.

\section{Children's perspectives on their neighbourhoods}


The final, definitive version of this paper has been published in Childhood - A Global Journal of Child Research, Vol. 20(1), February 1, 2013, pp.98-114, by SAGE Publications Ltd, available at http://online.sagepub.com . All rights reserved. CMaria João Leote de Carvalho (CESNOVA - FCSHUniversidade Nova de Lisboa, Portugal)

The ways children experience and build a sense of ownership of space are fundamental pillars for their involvement in the change of space, and thus, raise the residents' quality of life (Christensen and O'Brien (2003). In this study, the word 'neighbourhood' has a strong presence in all children's productions, ${ }^{3}$ unlike observed in other researches (Rasmussen \& Smidt, 2003).

Overall, when expressing their thoughts about their neighbourhoods the negative aspects overshadowed the positive ones (Figure 1). This overlap was particularly pronounced when they talked about 'people' $\left(\chi^{2}=125, \mathrm{p}<.05\right)$ and 'public equipment' $\left(\chi^{2}=85, \mathrm{p}<.05\right)$, and to a degree, somewhat lower but still significant, as they referred to the 'public spaces' $\left(\chi^{2}=31, \mathrm{p}<.05\right)$ and 'shops and services' $\left(\chi^{2}=31\right.$, $\mathrm{p}<.05)$. On the other hand, their 'house/homes' $\left(\chi^{2}=12, p<.05\right)$, 'schools' $\left(\chi^{2}=18, p\right.$ $<.05)$ and 'family' $\left(\chi^{2}=8, p<.05\right)$ were more positive. It is worth mentioning that there is almost no difference in how they represented the 'children' in this context. No significant gender differences were registered in all variables. 
The final, definitive version of this paper has been published in Childhood - A Global Journal of Child Research, Vol. 20(1), February 1, 2013, pp.98-114, by SAGE Publications Ltd, available at http://online.sagepub.com . All rights reserved. CMaria João Leote de Carvalho (CESNOVA - FCSHUniversidade Nova de Lisboa, Portugal)

Figure 1: Positive and negative evaluation of neighbourhoods by the children

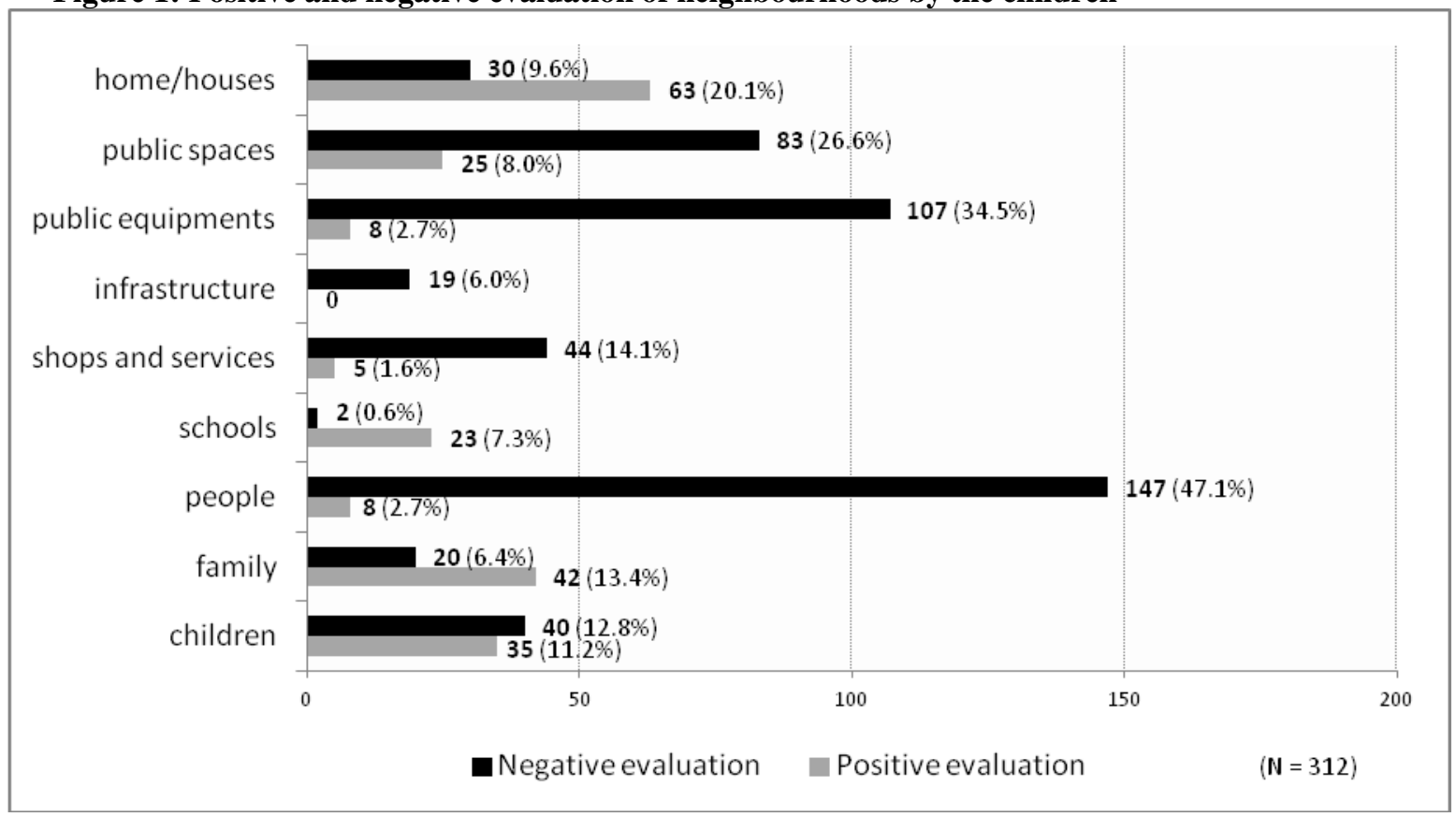

It is important to note that the most significant negative evaluation, expressed by almost half of the 312 participants (47.1 percent), is related to social interaction, specifically concerning 'people', in this case the adults with whom children interact or observe in daily life. Children turned out to be quite sharp regarding what they consider to be the greatest 'people' problems in their neighbourhoods, pointing out violence, disorders and crime. Regardless of gender or neighbourhood, adults' attitudes and behaviours are mostly seen as disruptive and disorderly. However, there were significant age differences $\left(\chi^{2}(1)=4.829, p<.05\right)$. The 6 to 9 years old were more critical and negative about 'people' than were the 10 to 13 -year-olds. 
The final, definitive version of this paper has been published in Childhood - A Global Journal of Child Research, Vol. 20(1), February 1, 2013, pp.98-114, by SAGE Publications Ltd, available at http://online.sagepub.com . All rights reserved. CMaria João Leote de Carvalho (CESNOVA - FCSHUniversidade Nova de Lisboa, Portugal)

Children have a clear idea about their expectations of adults' social roles and disparagingly referred to the existence of a large number of individuals who are distant from what they consider the reference model, suitable for the maintenance of trust and social cohesion. Children approach the concept of social actors assigned to each individual, and most shared the idea that improving a neighbourhood's quality of life goes through changes in the behaviour and attitudes of everyone living there.

Figure 2: My neighbourhood

'I don't like my neighbourhood ... In my neighbourhood we really need people's behaviours to be better, the biggest problem is people, people are... people do not like... all over there is theft, loud noise, fights, shootings, robberies and cars, and more stolen cars. I don't like it!' (boy, 10 years old, $4^{\text {th }}$ grade, Green Neighbourhood)

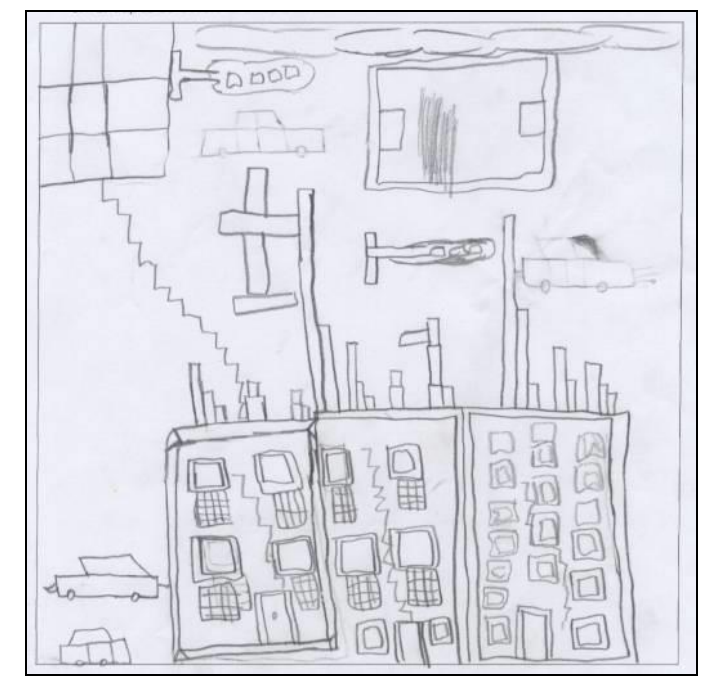

This idea is also associated to the important expression of a negative evaluation about 'public spaces' (34.5 percent; $n=76)$, something common in all the neighbourhoods, because it is within these kinds of spaces children located a wide range of physical and social disorders and violence. When referring to 'public equipment', boys and girls did not differ in their perspectives $\left(\chi^{2}(1)=0.367, p>.05\right)$, above all a 
The final, definitive version of this paper has been published in Childhood - A Global Journal of Child Research, Vol. 20(1), February 1, 2013, pp.98-114, by SAGE Publications Ltd, available at http://online.sagepub.com . All rights reserved. CMaria João Leote de Carvalho (CESNOVA - FCSHUniversidade Nova de Lisboa, Portugal)

negative one, intrinsically related to the lack of playgrounds, which have either not been built or because the two existing ones have been looted by residents, not necessarily children, but by adults and youth who have used it for other purposes. However there were significant age differences $\left(\chi^{2}(1)=5,533, p<.05\right)$ : the 10 to 13-year-olds complained less than the 6 to 9-year-olds.

Not surprisingly, many children ( $n=94 ; 30.2$ percent) asked for the construction of playgrounds in their neighbourhoods. A smaller, but still significant, percentage of children ( $n=37 ; 11.8$ percent) noted they also would like to have gardens, more trees and more flowers on the streets. The need for more street furniture, mostly litter bins, recycling containers and street lightings, was also pointed out. Some children, especially boys, highlighted the need to have a small soccer field. As found in other studies (O'Brien, 2003; Rasmussen, 2004), children's emphasis on the need to have better playing conditions and to improve leisure facilities cannot be dissociated from their desire to be included in the neighbourhoods and to have a public space for themselves.

Figure 3: My neighbourhood

'These are the buildings, the cars and the boys playing when there were slides and swings and seesaws. I used to go there to play but now there's nothing because they lay it all down and I don't know why. (...) A playground is very much needed here so we can have a space where we can go play. We need space to play, we can go to the street and there we have space, but then the balls go into the road and sometimes the cars are running so fast in street races that someone can be killed.' (girl, 7 years old, $1^{\text {st }}$ grade, White Neighbourhood)

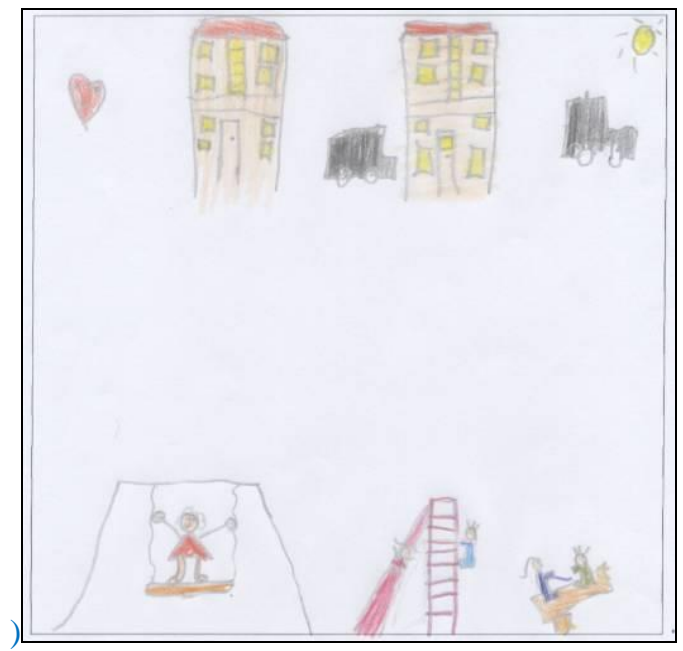


The final, definitive version of this paper has been published in Childhood - A Global Journal of Child Research, Vol. 20(1), February 1, 2013, pp.98-114, by SAGE Publications Ltd, available at http://online.sagepub.com . All rights reserved. CMaria João Leote de Carvalho (CESNOVA - FCSHUniversidade Nova de Lisboa, Portugal)

Associated to a notion of territoriality, a playground is a collective aspiration in all neighbourhoods, regarded as a social symbol which is perceived to be accessible to social groups living in other places. In other studies, it has been stated (Karsten, 2003: 471) 'playgrounds are the first arenas in which girls and boys learn to negotiate their behaviour in public'. The major complaint here is based on the perception of social discrimination for not having some of the classic elements of childhood worldwide: swings and slides. By not having playgrounds or any other specially designed areas for recreational use in their neighbourhoods, children are mainly sent to the street. On one hand, it gives them the possibility of fully exploring their physical and social environment, but it simultaneously exposes them to a range of other situations that are clearly more unfavorable and potentially generate different risks.

Given this scenario, one emphasizes the positive value attributed to the 'house/home'. This situation is not restricted to the children who have previously lived in disadvantaged conditions, in the slums, and still have memories of those times. Many of the others, born since their families have been living in these neighbourhoods, mostly girls (61.9 percent, $n=39)$, mentioned several positive aspects of their 'houses/homes'.

'I didn't like living in [slum's name] because there were many animals, cockroaches, rats... and rocks and sand everywhere. We had many... many animals... My home here is better and I have a room to myself and to my grandmother and over there, I didn't. My grandmother slept in a sofa in the living room.' (boy, 7 years old, $2^{\text {nd }}$ grade, White Neighbourhood)

'I really love my home, it's beautiful! I've always lived here and my mother too. I've a room to myself and I'm always playing there when my parents are cooking.' (girl, 8 years old, $2^{\text {nd }}$ grade, Yellow Neighbourhood) 
The final, definitive version of this paper has been published in Childhood - A Global Journal of Child Research, Vol. 20(1), February 1, 2013, pp.98-114, by SAGE Publications Ltd, available at http://online.sagepub.com . All rights reserved. CMaria João Leote de Carvalho (CESNOVA - FCSHUniversidade Nova de Lisboa, Portugal)

The most critical were those boys and girls who were mainly affected by the overcrowding of the houses, generally occupying a shared room by parents, children or even other relatives.

The spatial concentration of social disadvantage in these neighbourhoods is reflected through high rates of poverty, unemployment and dependence on social/financial state benefits, strong residential mobility, cultural heterogeneity and low educational and professional qualifications. Analysing concentrated poverty entails more than discussing the spatial concentration of poor people as a result of many public housing policies in western societies; it is more important to discuss the multiple risks that poverty represents (Sampson et al., 1999). Children can be identified by socio-economic disadvantage and apparently accept their social condition of 'being poor', recognizing their neighbourhoods as places of spatial concentration of socio-economic disadvantages, which can exclude them from participation in city life.

\section{Figure 4: My neighbourhood}

'It's a bad day in the neighbourhood! ... What we need in my neighbourhood is houses, more houses for people and a playground. Here what we have more are poor people, there's only poor, poor people, just poor...' (boy, 8 years old, $2^{\text {nd }}$ grade, Yellow Neighbourhood)

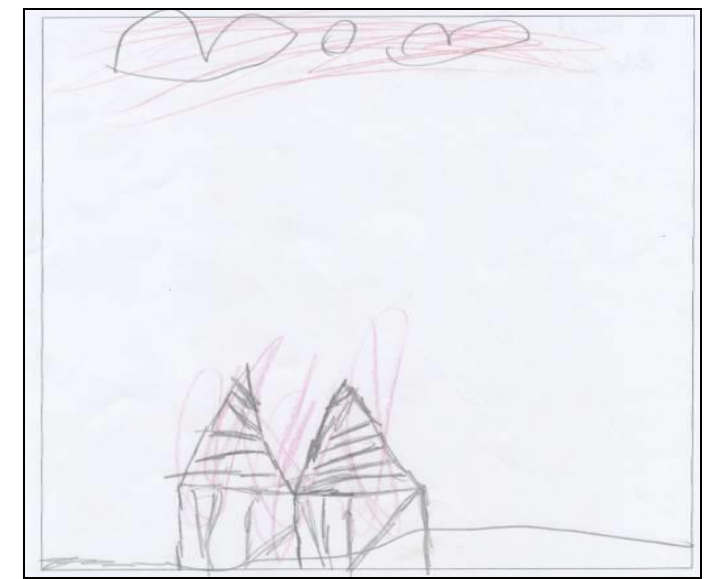


The final, definitive version of this paper has been published in Childhood - A Global Journal of Child Research, Vol. 20(1), February 1, 2013, pp.98-114, by SAGE Publications Ltd, available at http://online.sagepub.com . All rights reserved. CMaria João Leote de Carvalho (CESNOVA - FCSHUniversidade Nova de Lisboa, Portugal)

Social disadvantage of multiple forms can be manifested in a low level of confidence required in relation to 'others', which lowers residents' expectations to intervene on social control, and it also lower residents' expectations to take collective action aiming children's socialization (Sampson et al., 1997). Wherever children live, discovering the existence of the 'others' often implies raising questions about identity, difference, otherness and power. Taking into account the complexity of social life, the relations between cultural and ethnic groups are often conflicting. This is something that children become aware of pointing it out as one of the major problems, not only amongst those living inside and outside these neighbourhoods, but also between groups of residents.

\section{Figure 5: My neighbourhood}

'It's my home. In my neighbourhood there are many dogs and there are a lot of people I don't like. I want to say that I would like very much for the neighbourhoods to be improved. It's not that they only have bad things, but people have to be... have to be more friendly with each other, even if they are "black", “white” or "gypsies"...' (girl, 9 years old, $4^{\text {th }}$ grade, White Neighbourhood)

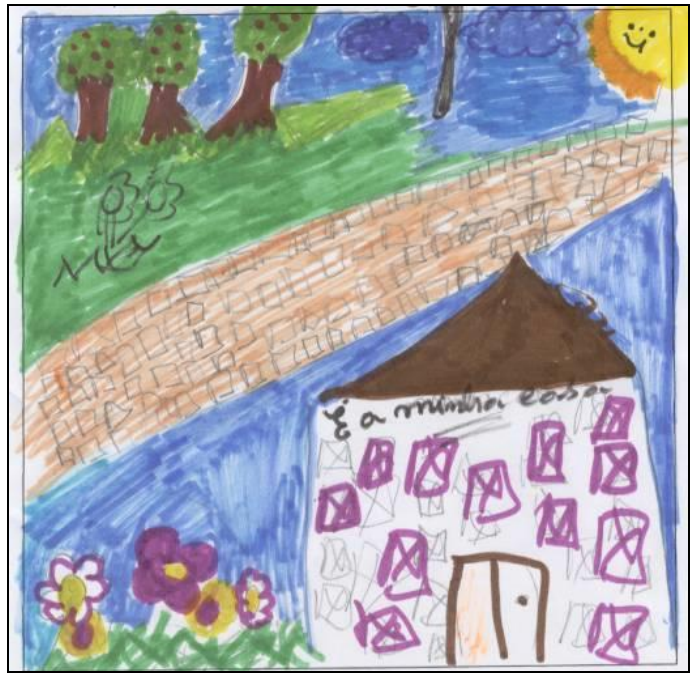

The fragmentation and heterogeneity of cultural dynamics in a given society leads to the idea of social cleavages and ongoing conflicts among different social groups, which 
can have a strong presence in children's lives (Parkes, 2007). Each child participates in his/her cultural group life through family, peers and those who are closest, establishing a dialectic relation between notions of 'self', 'we', the 'other' and 'others' from which daily action is built (Bennet Jr and Fraser, 2000).

\section{Crime, violence and disorders in daily life}

The most mentioned problem pointed out by children was crime (31.4 percent, $n=98)$. In their drawings, 6.2 percent $(n=20)$ of the children graphically represented a crime being committed in his/her neighbourhood, mostly in public spaces, but when they were asked to describe and talk about their own drawing many more situations related to crimes turned up, followed by different types of disorders and violence.

Figure 6: My neighbourhood

'This here is a man running over a little boy... On the other side is the youngster who killed the other near my house. He went home to pick up the gun and then came back and killed him... In the building there is a man shooting at his wife. He pushed her away and she fell out of the window. The neighbours called the firemen and there's nothing more... I don't like living here. There are too many sad things and it's very sad to live here. It's like this...' (girl, 9 years old, $3^{\text {rd }}$ grade, White Neighbourhood)

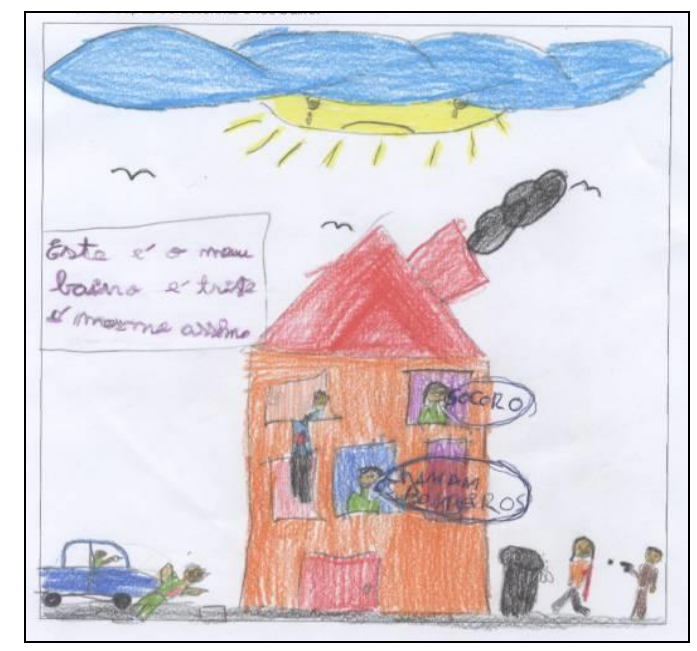


Morenoff et al. (2001) have argued that there is extreme inequality in the distribution of resources within cities. They ascribe this to economic factors and ethnic distribution resulting from the territorial concentration of social disadvantage and social isolation to which different social and ethnic groups are subjected, combined with the lack of positive changes in some neighbourhoods where informal social control is more justified, to some extent, due to the concentration of violence and crime rates.

When combining graphic and discursive levels, the street appears as a fundamental place in participants' lives, revealing the importance of access to public space. The street has a central place in children's socialization in these neighbourhoods; and for many it is 'the' most significant place since early ages (1-2 years old). Playing or staying on the street, predominantly without parental supervision, is an activity largely developed by many boys and girls. The street offers them multiple possibilities for exploration and discovery, enhancing their positive personal and social skills, but no less relevant is the high level of exposure to violence and crime in this context. Street conviviality and sociability are often crossed by other threats, emerging references to the lack of security, fear and danger in the use of public spaces.

As expected, children's forms of victimization in the neighbourhoods were subjects of particular interest and concern to the participants, with a special attention to violent deaths, such as during illegal car races (Figure 6). Another problem is domestic 
violence, which according to children's words seem to affect a significant proportion of the neighbourhood households.

'My father hit my mother, and then my mother tried to kill my father.' (girl, 8 years old, $3^{\text {rd }}$ grade, Green Neighbourhood)

'I cannot go to the study visit because, in my home, my father and my mother are always fighting and every day it's getting worse... I cannot go.' - said the boy (10 years old, $3^{\text {rd }}$ grade, Blue Neighbourhood)

'Do you think you can solve anything by staying?' - asked the teacher.

'Yes, I don't let my father beat my mother. I take him out of the way.' [field notes]

In several cases, children's places in the family seem to be exactly the opposite from what is expected, with the younger ones serving a parental role and acting to protect some of the adults. The violent acts may occur frequently and become perceived as less serious over time, in which they tend to gain visibility in all neighbourhoods, almost in a perspective of 'normalization' of violence. The use of guns and other weapons, in which dangerous dogs are included, can be enhanced by having easy access to them or by the knowledge of such situations in the place where children live, not only in public spaces, but also at their homes, by the hand of closest relatives.

'Robbery with a gun is nothing special!' (boy, 10 years old, $3^{\text {rd }}$ grade, Blue Neighbourhood)

'The dog is a pit-bull who bites people and causes harm. (...) They are using the dogs to scare people, many dogs are used for fights and to do harm to people.' (boy, 7 years old, $2^{\text {nd }}$ grade, Yellow Neighbourhood)

Children paid particular attention to physical disorders, such as graffiti on buildings and public equipment, abandoned cars (or 'stolen', to use the children's own words), garbage on the streets, deteriorated sidewalks and broken windows and doors. No less 
relevant were the forms of social disorder children singled out: loud noise on the streets, day and night, the sale and drinking of public alcoholic beverages mostly in dead end streets, fights, conflicts, verbal harassment and threats.

\section{Figure 7: My neighbourhood}

'This is the building where I live! People in my neighbourhood are always fighting, always making loud noise, and fighting... Ah! Here we need flowers, a garden, there is no garden over here... there's no quietness, there's no good life! What we really miss more is peace because there are a lot of fights, people making noise and interested in going to fight with someone. The other day, it was even worse. At night, Laura's mother was taken to the police station, then a police car came and she went back home and when returning she wanted to beat the policeman. Then, Manuel's mother went home to pick up an axe, but then my mother didn't let me see any more. She told me to come straight home, and I went.' (girl, 9 years old, $4^{\text {th }}$ grade,

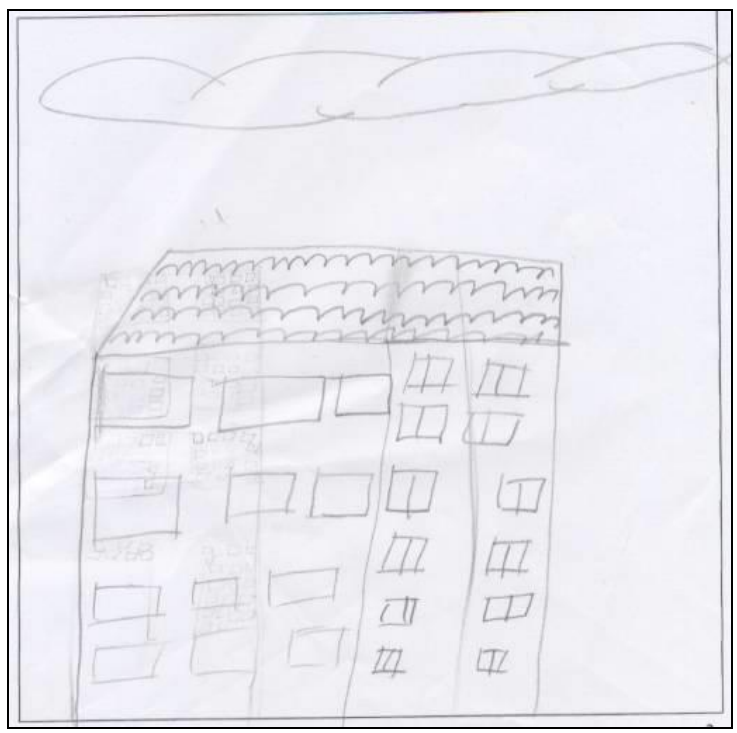
Pink Neighbourhood)

These are some of the main signs repeatedly brought up during the narratives with reference to the drawings, descriptions where children pointed out not only the involvement of residents, but also sometimes individuals and groups from other neighbourhoods in the Lisbon Metropolitan Area, in what seems to be a struggle over the territory or criminal activities that undermine the effectiveness of informal social control. A great interest and concern on the street lighting was also expressed. It was 
often inoperable, as a result of vandalism, which conceals a variety of actions, from residents' acts of crime to making police intervention more difficult.

'I wish I could play in the garden but now you can't play at all. There is no street lighting. Almost everything is broken and damaged. (...) Going out at night is dangerous because it's very dark and there's no more streetlights working.' (boy, 2 years old, $2^{\text {nd }}$ grade, Yellow Neighbourhood)

Regarding violence and physical and social disorders, not all children were passive spectators. It was possible to identify how some were active in these actions, holding a specific role that was generally known and commented upon by other children and residents. This is a clear example that childhood cultures generated here are underpinned by a culture of violence, integrating both intra and intergenerational contributions.

[in the case of the street lighting] 'Yesterday, they [some adults and young people] sent him [boy, 9 years old] again to turn off the lights, to turn off everything so the police won't see anything (...) and he goes. He always goes, there he goes ... he has done it since he was much younger (...) and the other night, he also did it for us to play cops and robbers (...) Then, so everything was dark and nobody knew where everyone was hiding.' (boy, 10 years old, $4^{\text {th }}$ grade, Green Neighbourhood)

The deviant influence of adults towards children easily turned into a particular knowledge of violence that could be used amongst the younger ones for their own purposes, especially fun and play. Moreover, talking about it could give them personal recognition at a local level and increase their social status through the involvement in violent practices (Carvalho, 2010). 


\section{Conclusions}

This study confirms the importance of discussing how children see the city in order to reform cities within a child-sensitive framework (Christensen and O'Brien, 2003). Children's agency to analyse and participate in social life has been clearly expressed; in the present study, their awareness of social problems was high and their willingness to be heard and to intervene was strongly expressed. Through the discussion of the social context where they live, children's drawings can be understood as one of the most challenging approaches in the field of childhood studies, in a process where it is essential to regard and attend to children's own words describing their works (Kostenius, 2011).

More play space, better public space and public equipment maintenance and more security were the children's priorities. Overall, children revealed a special concern over the neighbourhoods' sustainability, approaching the idea of a 'healthy city' (Hancock and Duhl, 1999, cit. in Oliveira et al. 2004: 97), which refers to urban spaces in which residents, both adults and children, are continually creating and improving the physical environment and strengthening the community's social networks and resources in order to achieve a better quality of life.

Children were eloquent when stating their views of social relations; most complained about living in their neighbourhoods, describing how social and spatial segregation and high exposure to violence and disorder affect them. Neighbourhood's spatial 
segregation, in relation to other socially differentiated residential areas, was worsened by the degradation of public spaces and equipment, which is regarded as a sort of violence, whether by the physical limitations imposed or the symbolic effects of social relations amongst residents and non-residents. There were no significant gender differences, which might suggest boys and girls are increasingly present in the same spaces and subject to the same tensions and conflicts in these neighbourhoods. This can be understood how both boys and girls are increasingly challenging traditional children's gender behaviours in the Portuguese society (Almeida, 2009).

When comparing risks in different urban settings, Benbenisthy and Astor (2005) have argued it is precisely those children living in socially disadvantaged neighbourhoods who are more likely to be victims of violence. In addition, this study's discussion on children's insights on urban violence lead us to recognize that as a part of the context where they come to grow, violence appears 'normalized' to many children. This 'normalization' strengthens the risk of children's devaluation of the seriousness and effects of violent acts and, not surprisingly, some participate in it since very young ages. Ultimately, children's social development through violence is already structuring how they will interact with peers and adults and it will be reflected in children's future roles in society.

In this process, a special attention should be paid to the use of public spaces by children and adults. The street has a central place in children's socialization in these 
neighbourhoods and parental supervision does not always provided their adequate protection; often, both boys and girls referred how were involved in social disorders and violence together with their own parents or relatives. This forces us to question the nature of the existing social networks and how residents' lack of intervention on social control reflects insufficient collective action to improve children's socialization, which may endanger social cohesion (Morenoff at al., 2001). Up to a point, this might explain why younger children (6 to 9 years old) tend to be more critical on their perspectives than the older ones, who probably become accustomed to living within a violent social framework. These are residential areas where one identifies a wide range of social problems, however, no less important is to note that these problems do not lie or develop just inside them, and cannot be analysed or be prevented without taking into account other social systems (public education, health, social welfare, public safety and justice) and social policies effectiveness in the country.

\section{Funding}

This work was supported by the Fundação para a Ciência e Tecnologia (SFRH/BD/43563/2008).

\section{Acknowledgement}


The author gratefully acknowledges the Reviewers and the Editorial Board for their valuable comments on the earlier version of this article.

\section{Notes}

${ }^{1}$ We refer to social disorders as social behaviours 'considered threatening, such as verbal harassment on the street, open solicitation for prostitution, public intoxication, and rowdy groups of young males in public. By physical disorder I refer to the deterioration of urban landscapes - for example, graffiti on buildings, abandoned cars, broken windows, and garbage in the streets.' (Sampson, 2002: 224).

${ }^{2}$ Translation from Portuguese.

${ }^{3}$ Children's original language and expressions are retained as much as possible.

\section{References}

Almeida, AN (2009) Para uma Sociologia da Infância. Jogos de Olhares, Pistas para a Investigação. Lisboa: Instituto de Ciências Sociais.

Anning, A and Ring, K (2004) Making Sense of Children's Drawings. Glasgow: Open University Press.

Benbenisthy, R and Astor, RA (2005) School Violence in Context: Culture, Neighbourhood, Family, School and Gender. New York: University Press.

Beck, U (1992) Risk Society. Towards a New Modernity. London: Sage Publications.

Bennet, Jr, DM and Fraser, M (2000) Urban violence among African-American males: integrating family, neighborhood, and peer perspectives. Journal of Sociology and Social Welfare, Volume XXVII(3): 93-117. 
Body-Gendrot, S (2001) Les Villes. La Fin de la Violence? Paris: Presses de la Fondation Nationale des Sciences Politiques.

Carvalho, MJL (2010) Do Outro Lado da Cidade. Crianças, Socialização e Delinquência em Bairros de Realojamento, Phd Thesis in Sociology, FCSH, Universidade Nova de Lisboa. Available at: http://test01.rcaap.pt/handle/10362/6132

Christensen, $\mathrm{P}$ and O'Brien, $\mathrm{M}$ (eds) (2003) Children in the City. Home, Neighbourhood and Community. Oxon: Routledge.

Corsaro, W (1997) The Sociology of Childhood. Thousand-Oaks-California: Pine Forge Press.

Ennew, J (1994) Time for children or time for adults? In: Qvortrup, J; Bardy, M; Sgritta, G and Wintersberger, H (eds) (1994) Childhood Matters. Social Theory, Practice and Politics. Vienna: European Centre for Social Welfare Policy and Research, 125-144.

Gardner, H (1990) Gribouillages et Dessins d'Enfants. Leur Signification Hayen: Mardaga.

Gill, T (2007) No Fear. Growing Up in a Risk Averse Society. London: Calouste Gulbenkian Foundation, United Kingdom Branch. 
Holloway, SL and Valentine, G (2000a) Children's Geographies. Playing, Living, Learning. London: Routledge.

Holloway, SL and Valentine, G (2000b) Spatiality and the new social studies of childhood. Sociology, 4(34): 763-783.

James, A and Prout, A (1990) Constructing and Reconstructing Childhood: Contemporary Issues in the Sociological Study of Childhood. London: The Falmer Press.

Karsten, L (2003) Children's Use of Public Space. The Gendered World of the Playground, Childhood, 10(4), 457-473

Katz, C (2005) The terrors of hypervigilance: security and the compromised spaces of contemporary childhood, In: Qvortrup, J (ed) (2005) Studies in Modern Childhood. Society, Agency, Culture. New York: Palgrave MacMillan, 99-144.

Kingston, B; Huizinga, D and Elliot, DS (2009) A Test of Social Disorganization in High-Risk Urban Neighborhoods. Youth and Society, 41: 53-79.

Kostenius, C (2011 Picture this - our dream school! Swedish schoolchildren sharing their visions of school. Childhood, vol. 18, 4: 509-525.

Lee, N (2001) Childhood and Society. Growing Up in an Age of Uncertain. Maidenhead: Open University Press.

Madge, N (2006) Children These Days. Bristol: The Policy Press. 
Mayall, B (2002) Towards a Sociology for Childhood: Thinking from Children's Lives. Maidenhead: Open University.

Morenoff, JD; Sampson, RJ and Raudenbush, SW (2001) Neighborhood inequality, collective efficacy, and the spatial dynamics of urban violence. Criminology, Volume 39(3): 517-558

Neto, C (2005) A mobilidade do corpo na infância e desenvolvimento urbano: um paradoxo da sociedade moderna". In Rodrigues, D (ed) (2005). O Corpo que (Des)Conhecemos. Cruz Quebrada: Edições FMH, 15-32.

O'Brien, M (2003) Regenerating children's neighbourhoods: what do children want? In: Christensen, $\mathrm{P}$ and O'Brien, M (eds) Children in the City. Home, Neighbourhood and Community. Oxon: Routledge, 142-161.

Oliveira, CS; Wolff, MP; Conte, M. and Henn, RC (2004) Violência e Cidade: existiria uma geografia do crime? O Público e o Privado, nº4: 87-101.

Parkes, J (2007) The multiple meanings of violence: children's talk about life in a South African neighbourhood. Childhood, Vol. 14(4): 401-414.

Popkin, SJ; Gwiasda, VE; Olson, LM; Rosenbaum, DP and Buron, L (2000) The Hidden War. Crime and Tragedy of Public Housing in Chicago. New Jersey: Rutdgers University Press.

Rasmussen, K (2004) Places for children, children's places. Childhood(11): 155-173. 
Rasmussen, K and Smidt, S (2003) Children in the neighbourhood. In: Christensen, P and O'Brien, M (eds) Children in the City. Home, Neighbourhood and Community. Oxon: Routledge, 82-100.

Sampson, RJ (2002) Transcending tradition: new directions in community research, Chicago style. Criminology, Volume 40(2): 213-230.

Sampson, RJ; Morenoff, JD and Earls, F (1999) Beyond social capital: spatial dynamics of collective efficacy for children. American Sociological Review, Vol. 64: 633660.

Sampson, RJ and Laub, JH (1994) Urban poverty and the family context of delinquency: a new look at structure and process in a classic study. Child Development(65): 523-540.

Sarmento, MJ (2007) Conhecer a Infância: os Desenhos das Crianças como Produções Simbólicas. Lição de Síntese de Provas de Agregação, Braga, Universidade do Minho.

Valentine, G (2004) Public Space and the Culture of Childhood. Aldershot: Ashgate Publishing Limited.

Wyness, M (2006) Childhood and Society. An Introduction to the Sociology of Childhood. New York: Palgrave MacMillan. 